\title{
Jobofifetime
}

\section{Around the world in 100 days}

I f you love to travel and can roll with the punches as well as the waves, shipping out on Semester at Sea (SAS) may be your job of a lifetime. Three times a year, intrepid librarians set out on voyages around the world on board the $23,000-$ ton SS Universe Explorer: For 100 days the Universe serves as the floating campus for approximately 650 undergraduates, 60 faculty and staff and their dependents, 30 senior passengers, and 125 officers and crew.

Each voyage includes visits to nine to ten countries located throughout Africa, Asia, Europe, and Latin America. The destinations are very differ-

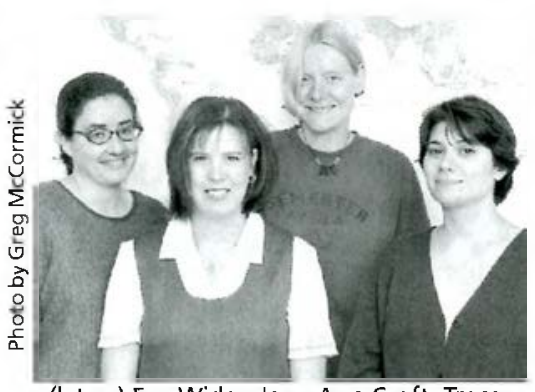

(I. to r.) Eve Wider, Jean Ann Croft, Tracey Olanyk, and Anna Mihalega: librarians whose job of a lifetime was a semester at sea.

world's largest floating academic library, housing a collection of approximately 13,000 items. The collection supports more than 70 academic courses spanning 22 fields and a field program of 3-to-6 day country visits, but also includes recreational materials and a small children's section.

Collection development is a challenge for Olanyk, with 25 to 30 new faculty every semester, new destinations and new courses, and only 2 or 3 days in port to get everything set up in between voyages. Currently, she is acquiring material for four new Pacific Rim destinations for the summer 2003 voyage.

Until very recently, ent from the usual cruise ship stops. The spring and fall voyages employ a head librarian, who must be from SAS's academic sponsor, the University of Pittsburgh (UP), and an assistant librarian who can be from anywhere in the world. (The shorter 65-day summer voyage is staffed only by a head librarian and uses a smaller ship.) The SAS experience is highly sought after, and often transformative in both professional and personal dimensions.

Jean Ann Croft, Anna Mihalega, Tracey Olanyk and Eve Wider, all UP librarians, shared their experiences circumnavigating the globe with SAS.

\section{Batten down the books}

Their domain was the C.Y. Tung Library (named for SAS's chief benefactor), the "most beautiful part of the ship," commented both Wicler and Croft. According to Olanyk, who now serves as SAS's permanent land-based librarian, it is the

there was no Internet access and just a handful of CD-ROM databases. Wider shared that the "students were shocked that they didn't have Internet access but impressed with what could be found in print sources." For some questions, the librarians would have to creatively comb the collection when the resources they were accustomed to using weren't available.

The library space, adapted from the ship's casino, retains much of its lively décor; librarians "serve up" materials and provide reference from behind the original bar. The library's position at the fore of the ship affords beautiful views from its many windows, but this position also subjects patrons and staff to the bumpiest ride on the ship. When rough seas are anticipated, the librarian must physically secure the books and videos. On Croft's voyage, some of the safety doors gave way, which made for a lot of reshelving. 


\section{Don't forget to pack your sense of humor}

When I asked the SAS librarians, "What is the most important qualification for this job?" they all agreed it was being flexible and having a good sense of humor. As Wider said, "Once you set foot on the ship, you're not in control of where you're going anymore. World events happen." Depending on the political situation, the ship's itinerary may change at very short notice.

During Wider's fall 2000 voyage, the USS Cole was bombed in the port of Aden. Instead of going through the Suez Canal and visiting Egypt, Spain, and Croatia, the ship went to South Africa, Kenya, and Brazil. This was a challenge for the faculty, who now had to teach about Africa, and for Wider, who helped them quickly prepare with the resources at hand.

Wider was luckier than one librarian in the $1980 \mathrm{~s}$ who, due to a similar rerouting, had to perform emergency collection development. That librarian ended up scouring the Indian city of Chennai for English-language materials

\section{Semester at Sea Librarian}

Where: C.Y. Tung Library

S.S. Universe Explorer

Somewhere in the world

\section{For more information, visit:}

hatp:/wow semesteratsea.com/ on Africa.

On Mihalega's voyage, the executive dean conducted a midnight raid on the library when the ship unexpectedly had to reverse course and proceed to the Seychelles instead of Kenya. Relying on the description in one of the travel books, she briefed the students and staff the next morning that they were "headed for paradise."

\section{It's a people job}

Another very important qualification is enjoying public service and working with undergraduates. "It's like living in a floating dorm for 100 days," said Wider, while Croft and Olanyk both talked about the "special community that forms on board." Mihalega did wam, "it's not an epiphany every other minute ... there's a lot of traditional old-fashioned library work." Reserves, circulation, reference, and troubleshooting make up the daily routine.

The library is open from 8 a.m. to 11 p.m., except when the ship is in port, which works out to be about half the voyage. Sudent workers do help relieve the two librarians during their shifts. As one of the few large public spaces on the ship, the library is always busy- "as busy as the main library during exams all the time" as Wider de- around her. Olanyk summed it up by saying, "You can't go to these countries and see the people and cultures without coming away more aware. You don't realize how much you've done when you're in the midst of it. And it's not until you return that you find out how much it has affected you."

\section{Returning home}

All the librarians commented that it's hard to come back. Wider observed, "You've changed-you've seen the world, literally, but everything else has basically stayed the same." For Mihalega, returning from the fall 2001 voyage, the events of September 11 had profoundly changed the country she had left 100 days before. Some libratians return to their jobs newly reinvigorated, while others, in time, move on to different careers. SAS makes people unafraid to pick up and do something different. Many have a newfound appreciation for America and realize how much we take for granted. Former shipmates stay in touch. through e-mail and reunions. Most of the four librarians said that the full impact of the SAS experience only becomes clear over time. Returning may be hard, but every one of them would do it again, in a heartbeat. "Where else are you going to be paid to go around the world?" 